\title{
LA INCLUSIÓN DEL GÉNERO Y LA DISCAPACIDAD EN EL CURRÍCULUM DE LA ESCUELA DE TRABAJO SOCIAL, SEDE RODRIGO FACIO, UNIVERSIDAD DE COSTA RICA
}

\section{INCLUSION OF GENDER AND DISABILITY IN THE CURRICULUM OF THE SCHOOL OF SOCIAL WORK, RODRIGO FACIO, UNIVERSITY OF COSTA RICA}

\author{
Marcela Ramírez Morera ${ }^{1}$ \\ marcela.ramirez@ucr.ac.cr
}

Fecha de recepción: 18 febrero 2014 - Fecha de aceptación: 14 julio 2014

\begin{abstract}
Resumen
El presente artículo discute la importancia de incluir las perspectivas de género y discapacidad en el currículum de la carrera de Trabajo Social de la UCR, mediante la identificación de los conocimientos que la población estudiantil de esta unidad académica tiene acerca de las temáticas de género y discapacidad. Aunado al proceso de concientización de este mismo grupo en dichas realidades.

De igual manera, se destaca las conceptualizaciones de violencia estructural, simbólica, discapacidad y género, además de las diferentes manifestaciones de dicha violencia en el ámbito académico, seguido por una descripción del proceso metodológico desarrollado en la investigación, el cual describe las personas participantes, las estrategias de recolección de información y algunos detalles de las fases experimentadas en la indagación realizada.

Finalmente, esta publicación destaca una serie de conclusiones y recomendaciones emanadas de la población participante en la investigación, las cuales son pilares fundamentales para orientar el accionar de las distintas unidades académicas, y en particular, la Escuela de Trabajo Social de la Universidad de Costa Rica.
\end{abstract}

Palabras claves: género, personas con discapacidad, violencia estructural y simbólica, currículum, trabajo social.

\section{Abstract}

This article discusses the importance of including gender perspectives in the curriculum and disability Career Social Work UCR, by identifying the knowledge that students of this academic unit has about gender issues and disability. In addition to the process of awareness of this group in such realities. Similarly, the conceptualizations of structural, symbolic violence, disability and gender, in addition to the various manifestations of such violence in academia is highlighted. Followed by a description of the methodology developed in the research, which describes individuals involved, strategies for collecting information and some details of the phases encountered in the investigation conducted Finally, this publication highlights a number of conclusions and recommendations of the population participating in the research, which are fundamental pillars to guide the actions of the various academic units and in particular the School of Social Work at the University of Costa Rica.

Key Words: gender, disability, structural and symbolic violence, curriculum, social work. 


\section{Introducción}

Históricamente las sociedades se han desarrollado bajo la ideología del patriarcado que invisibiliza las diversidades sociales, entre ellas la de las mujeres, las cuales se encuentran mediatizadas por los preceptos masculinos que transversalizan nuestras etnias, opciones sexuales, grupos etarios, condiciones de discapacidad, socioeconómicas y locales, por lo tanto la influencia de las ideas androcéntricas se reproducen en las distintas instituciones de la sociedad civil; un ejemplo de ello son las entidades de educación superior, las cuales omiten la incorporación de las perspectivas de género y discapacidad en los currículos universitarios, cuyos resultados son la violencia estructural y simbólica.

Según Herrero (1998), la violencia estructural se suele definir por medio de dos términos: entendiendo por violencia el uso de la fuerza para forzar o mediatizar las conductas humanas, y la palabra estructural, la cual se refiere a un orden constituido (mecanismos de control social) de una sociedad. Así, la violencia estructural es de naturaleza encubierta y sistémica, engloba una serie de conductas resultantes de un medio social que ofrece oportunidades desiguales a todas las personas.

De este modo, la violencia estructural se genera a través de acciones cotidianas que la misma sociedad ejerce sobre las personas y que al mismo tiempo impacta nuestras realidades como mujeres, cuyas consecuencias son permanentes y continúan durante largos periodos de la vida. Estas estructuras reproductoras de este tipo de violencia se desarrollan de manera distinta en diversas instituciones de la sociedad civil, entre ellas las universidades.

El género y la discapacidad tienen su génesis en el tejido social, por ejemplo, el género como una construcción socio-cultural fundamentada en las diferencias biológicas, y la discapacidad como una elaboración social y restricción en la participación. Por ende, son características que socialmente se traducen en desigualdad y discriminación, las cuales son reproducidas en las instituciones con discursos androcéntricos, como lo son las entidades de educación superior.

En la actualidad, se vive en un mundo diverso, donde el respeto a las diferencias se encuentra enmarcado en los derechos humanos, los cuales transversalizan los distintos ámbitos de participación social, entiéndase salud, empleo, seguridad social, vivienda y educación. Por tanto, es de suma importancia analizar e investigar las distintas cotidianidades de mujeres y personas en condición de discapacidad, específicamente en el ámbito educativo.

La educación es parte de la formación personal y diaria, como tal, se encuentra presente en la mayoría de la población en casi un cuarto de tiempo de su vida o más; se dirige a todas las personas que componen la diversidad social, mujeres, hombres, niños/as, personas adultas mayores, en condición de discapacidad, poblaciones indígenas, migrantes, entre otras. No obstante, este ámbito continúa con la ideología dominante (Ramírez, 2010).

Por su parte, el género y la discapacidad no deben ser asumidas desde la vulnerabilidad, sino desde la necesidad de plantear un nuevo orden a través de la participación social, la visualización de las mujeres con discapacidad, y la posibilidad de participar de forma activa en la toma decisiones. Al no incluir las perspectivas de género y discapacidad en los distintos currículos educativos, se ignora y naturaliza las acciones sociales, como chistes, cuentos, comentarios, imágenes, programas, proyectos, recursos didácticos, y bibliografía, entre otros; generando violencia simbólica al invisibilizar las necesidades y especificidades de las mujeres y personas en situación de discapacidad.

En esta misma línea Aguilar (2002), refiere que la violencia simbólica de género se encuentra en la estructura de representaciones simbólico culturales impuesta por los sistemas socioculturales construidos y mantenidos desde el andrologocentrismo, el cual es jerárquico y patriarcal, sancionador de toda persona que no acepta ni ingresa en su estatuto significativo, por medio de actos discriminatorios.

Asimismo, cita que las diferentes expresiones de la sobrerrepresentación y sobrevalorización de lo simbólico masculino frente a lo simbólico femenino, es violencia simbólica de género, lo cual inmoviliza y descalifica al género femenino para representarse a sí mismo y a su propio mundo (Aguilar, 2002). 
Parafraseando a la autora, la violencia simbólica evidencia la imposición de significados, valores, parámetros, conductas concebidas como válidas y legítimas por el tejido sociocultural, que someten a las personas a partir de una situación diferenciada que las discrimina, imponiendo referentes simbólico culturales, tanto en la esfera subjetiva como en el ámbito social, que perpetúan esta condición (Aguilar, 2002).

Desde la óptica de Aguilar y citando a Bourdieu, "las personas nacemos en un mundo que ha aceptado y establecido como estándares una serie de representaciones simbólico culturales, que se transforman en un común denominador. Estas premisas son los referentes de una historia incuestionable, la obligación de un orden lógico del universo que se moldea a partir de lo masculino y que recae como condicionante sobre lo femenino". (Aguilar, 2002)

"El mundo que se estructura a partir de la lógica de la dominación masculina o andrologocentrismo tiene tantas raíces en el comportamiento sociocultural, que se constituye en el accionar normal del pensar simbólico cultural de la sociedad, al imponer el modelo logocéntrico como una manifestación natural del desarrollo de la realidad" (Bourdieu, 1995. Citado por Aguilar, p. 156 2002).

También, Aguilar (2002) menciona que la naturaleza sociocultural de la violencia simbólica actúa en dos planos que se entremezclan y reproducen:

1. La percepción subjetiva, donde se entretejen pensamientos, creencias, experiencias, valoraciones, imposiciones del deber ser/hacer individual, significados individuales, situaciones de vida, identidad personal, entre otras (Aguilar, 2002).

2. La clasificación objetiva, la cual es colectiva y social, Bourdieu la denomina "campo". Las estructuras del orden sociocultural son históricamente definidas y determinantes, impregnadas por jerarquizaciones, valoraciones y estereotipos que se convierten en imposiciones tomando como referencia una jerarquía de valores duales de definición diferenciada y preestablecida para hombres y mujeres, que define e impone el "deber ser/hacer/decir sociocultural" de lo masculino y femenino, con el privilegio de lo masculino. También, es donde el control social se ejerce, gracias a ciertas instituciones legitimadas socioculturalmente, para el cumplimiento de los mandatos, las disposiciones, las órdenes y los castigos (Aguilar, 2002).

Esta ideología condiciona nuestros cuerpos, mentes, ámbitos, personalidad individual y colectiva tan eficientemente, que se nos hace difícil nombrar, reconocer, concientizar, visibilizar, identificar y ni qué decir, de los intentos por cambiar el patrón simbólico cultural, muchas veces frustrante y engañoso. Este "darse cuenta" de algo que no está bien, que muchas veces no sabemos nombrar, es tramposo porque la violencia simbólica ejercida sobre el género femenino no está en los aspectos formales del sistema cultural, al menos en forma explícita o evidente (Aguilar, p. 58. 2002).

Las características generales de la violencia simbólica son:

- Tiene carácter de normalidad, como menciona Bourdieu, se presenta junto al "acto de conocimiento", un acto de "reconocimiento práctico" por parte de las personas que, mediante estos actos, hacen que se legitimen las prácticas subordinantes (Bourdieu, citado por Aguilar, 2000). Las cuales siguen una lógica de dominación aceptada de forma legítima por la totalidad del género femenino y masculino. Para Bourdieu cuando los dominados aplican a lo que les domina unos esquemas que son el producto de la dominación, es decir sus pensamientos y percepciones están estructurados de acuerdo con las propias ideologías (Aguilar, 2002).

- La existencia de un sentido de perpetuación, el orden sociocultural y las instituciones que lo conforman, al aparecer como estándar, tienden a perpetuar la ordenanza simbólica representativo, 
totalizando como única realidad sociocultural ese mandato simbólico cultural discriminativo y subordinante en relación con las mujeres (Aguilar, 2002).

Además, el autor describe las características de la violencia contra las personas con discapacidad de la siguiente forma:

- Algunas de las mujeres y personas con discapacidad no viven muchas de estas formas de violencia de manera consciente

Parafraseando a Jiménez (2003), esto ocurre a causa de la socialización que han recibido las mujeres y personas con discapacidad, pues observan las acciones violentas como naturales y que así debe ser por su condición. Ello no le permite estar consciente de que son formas violentas que inciden en su desarrollo holístico.

La mayoría de estas formas de violencia son mucho más serias, intensas y más frecuentes de lo que sabemos:

"Debido al silencio social que existe, los mitos y creencias acerca de las personas con discapacidad se tiende a pensar que son las formas correctas de relacionarse y que las personas con discapacidad se sienten a gusto. Por los mitos que existen acerca de las personas con discapacidad y la violencia muchas de las víctimas de violencia no reportan o denuncian unido a ello la baja autoestima que por lo general tiene debido a las agresiones constantes que sufren” (Jiménez, p. 55, 2003).

- Todas las formas de violencia benefician a quienes discriminan a las personas con discapacidad

Estas formas de violencia imposibilitan que las personas en condición de discapacidad alcancen una igualdad de oportunidades y sean partícipes de los recursos de la sociedad (Jiménez, 2003).

- El Estado y sus instituciones invisibilizan estas formas de violencia

La respuesta estatal y local es insuficiente para enfrentar la violencia en contra de las mujeres y personas con discapacidad. Los servicios gubernamentales discriminan a las personas en situación de discapacidad al no otorgarles igualdad de condiciones (Jiménez, 2003).

- Todas estas formas de violencia sirven para fortalecer la identidad de las personas con discapacidad

Se tienden a mantener a las mujeres y personas con discapacidad con baja autoestima convirtiéndolas en personas sumisas, dependientes, menos asertivas, porque temen ser víctimas de alguna forma de agresión y por haberlas sufrido en carne propia (Jiménez, 2003).

- Todas estas formas de violencia no se dan entre iguales "Estas formas de violencia se dan de una persona con más poder (social, cultural, económico, familiar, etario) contra una de menos poder" (Jiménez, p,55, 2003).

Al culminar el análisis de los tópicos conceptuales y fundamentales de la sistematización, es imprescindible conocer la interrelación entre género, discapacidad y violencia estructural; entonces: 
Cuadro 1

Diferencias y semejanzas entre género y discapacidad

\begin{tabular}{|c|c|c|}
\hline Categoría & Género & Discapacidad \\
\hline Diferencias & $\begin{array}{l}\text { Mayores manifestaciones de violencia. } \\
\text { Mayor explotación sexual } \\
\text { Triples jornadas laborales. } \\
\text { Vistas como objetos sexuales. }\end{array}$ & $\begin{array}{l}\text { Se enfrentan más barreras físicas. } \\
\text { Asignación de roles diferentes. } \\
\text { Múltiple discriminación. } \\
\text { La violencia es más sutil. }\end{array}$ \\
\hline Semejanzas & \multicolumn{2}{|c|}{$\begin{array}{l}\text { Pertenecen a un legado histórico generador de discriminación por siglos. } \\
\text { Son categorías sociales invisibilizadas. } \\
\text { Estamos envueltas en una ideología dominante y de subordinación. } \\
\text { Se tienen los mismos derechos y deberes. } \\
\text { Se participa en todos ámbitos sociales. } \\
\text { Se busca la igualdad. } \\
\text { El género y la discapacidad son categorías socialmente construidas. } \\
\text { Las características físicas son las que generan las diferencias. } \\
\text { Los mitos y estereotipos son semejantes. } \\
\text { Cotidianamente buscamos reconocimiento social. } \\
\text { Se es parte de una diversidad. }\end{array}$} \\
\hline Violencia estructural & \multicolumn{2}{|c|}{$\begin{array}{l}\text { Al incorporase de manera parcial las categorías de género y discapacidad al currículo de } \\
\text { la Escuela de Trabajo Social de la UCR, se reproduce la ideología patriarcal, entre otras, la } \\
\text { cual domina con su discurso de poder impregnado en los sistemas educativos, violentando } \\
\text { las realidades de aquellas personas que componen la diversidad social mediante la invisi- } \\
\text { bilización de las necesidades particulares. } \\
\text { Por lo tanto, es de suma importancia incluir el género y la discapacidad como un eje } \\
\text { transversal en los currículos universitarios para alcanzar el cumplimiento es los derechos } \\
\text { humanos, debido a que es un asunto público y político donde todas las entidades de la } \\
\text { sociedad civil deben asumir su responsabilidad }\end{array}$} \\
\hline
\end{tabular}

Fuente: elaboración propia.

\section{Estrategia metodológica: ¿Cómo?}

\section{Diseño de investigación}

Seguidamente, se describen los momentos a seguir para la realización de la presente investigación, la cual se efectuó de acuerdo con el paradigma cualitativo, debido a que el estudio se centró en una situación particular, no se pretende generalizar los resultados. Además, busca comprender e interpretar dicha realidad (Chaves, Díaz y García, 2007).

Los principios del enfoque cualitativo según Chaves, Díaz y García (2007) consisten en:

- Comprender el contexto sociocultural: en este estudio en particular, los aportes teóricos del grupo de estudiantes de cuarto año de Trabajo Social están impregnados por las creencias, costumbres, ideologías y tradiciones del estudiantado. 
- La realidad en su diversidad: en la presente investigación se busca interpretar un conjunto de realidades, comprendido por las experiencias y condiciones relacionadas con la etnia, las creencias religiosas, la opción sexual, el género y la discapacidad, entre otras manifestaciones de la cuestión social pertenecientes a cada estudiante.

- Las relaciones sujeto-tema de estudio: el conocimiento adquirido es preciso, debido a la relación cercana de la facilitadora y el grupo de estudiantes.

La sistematización se fundamentó en la perspectiva del método fenomenológico, el cual, tiene el objetivo de conocer el significado de los conocimientos previos del grupo participante (Chaves, et al. 2007).

Estas mismas autoras refieren que la investigación fenomenológica tiene como finalidad describir, detallar, comprender el fenómeno; no busca explicar las relaciones causales, ni la experiencia de determinada situación (Chaves, et al. 2007).

La indagación en estudio utiliza este fundamento fenomenológico, con la intención de conocer el significado de la perspectiva de género y de discapacidad que tiene el estudiantado de Trabajo Social. Además, identificar como los enfoques de género y discapacidad pueden influir en su formación académica.

Se recurre a la metodología de investigación-acción, la cual busca "construir conocimientos y formas de conocer", desde las propias personas involucradas en el problema de investigación; así mismo, tiene una connotación educativa y práctica pedagógica, la cual permite reflexionar y actuar sobre las experiencias cotidianas con el objetivo de encontrar alternativas de solución (Chaves, et al. 2007).

Este estudio se desarrolló con el método anteriormente citado, porque se usan técnicas que generan conocimientos nuevos, los cuales propician distintas propuestas para la construcción de estrategias que incorporen la perspectiva de género y discapacidad en el currículum.

\section{Participantes}

La sistematización se realizó con un grupo de 25 estudiantes de cuarto año de la Escuela de Trabajo Social, de la Universidad de Costa Rica, Sede Rodrigo Facio, dentro del curso Teoría y Métodos para la intervención del Trabajo Social VI.

\section{Técnicas de recolección de datos}

Se desarrolló sesiones socioeducativas, talleres, revisión documental y entrevistas a los y las coordinadores/as de nivel.

\section{Proceso metodológico}

El proceso investigativo se lleva a cabo mediante la vivencia de distintos momentos, a saber:

- Primer momento

Diagnóstico y reconocimiento de la situación inicial: esta se inició mediante una revisión bibliográfica, la cual consistió en una búsqueda de la misma sobre los contenidos relacionados con la temática en estudio. Se revisaron bases de datos autorizadas de revistas científicas indexadas y se visitó las diferentes bibliotecas de la Universidad. Asimismo, se categorizó la bibliografía pertinente a la investigación, para extraer los insumos teóricos que completaran los antecedentes del estudio. 
- Segundo momento

Desarrollo de un plan de acción: en esta etapa se elaboraron los antecedentes, marco conceptual, estrategia metodológica; esta última se compone de problema de estudio, objetivo, participante, preparación de técnicas.

Del mismo modo, se elaboró las diversas actividades que se comprendieron en las distintas sesiones educativas aplicadas al grupo de participantes.

- $\quad$ Tercer momento

Actuación para poner en práctica el plan: surge mediante el análisis de la información y la aplicación de los instrumentos, ya sea sesiones educativas, o talleres y entrevistas a la población participante. Además, se ordena y categoriza los datos recabados en las actividades anteriores, paralelamente con el desarrollo del diario de campo.

Seguidamente, se procedió a discutir los datos recolectados durante los diferentes espacios de discusión y reflexión, los cuales se extendieron alrededor de una hora y cuarenta minutos, durante seis sesiones. Posteriormente, se realizó una retroalimentación de la información recolectada a los/as participantes, de tal manera, que permita la validez y confiabilidad de la investigación.

\section{- Cuarto momento}

Reflexión sobre los resultados: el análisis se realizó de acuerdo con las técnicas aplicadas en las diferentes sesiones, por ejemplo, mediante los collage, trabajos grupales, la aplicación de una encuesta, frases incompletas, metaplan y exposiciones con diapositivas.

Posteriormente, se efectuó una comparación con los fundamentos teóricos, los cuales permitieron una confrontación e interpretación teórica.

En este período se plantearon las conclusiones y recomendaciones que surgían del análisis de la información, se presentaron los datos recabados públicamente junto con el informe escrito final, para concluir el proceso investigativo.

\section{Discusión de la información}

Seguidamente, se describe algunos insumos teóricos, los cuales se relacionan con los conocimientos brindados por la población participante.

\section{Las protagonistas}

Las estudiantes en su totalidad son mujeres que oscilan entre los 20 y 24 años, son residentes del área metropolitana, se encuentran en cuarto año de carrera y realizando su práctica profesional en los ámbitos de salud, justicia y asistencia. El 96\% no realiza una actividad laboral, el 92\% se encuentran casadas y solamente el $8 \%$ tienen hijos o hijas.

En relación con la pregunta si se sienten discriminadas por su condición de mujer, el 8\% menciona que sí, y el 92\% responde negativamente. Por lo que se puede deducir que las estudiantes han recibido una escasa capacitación sobre las teorías de género y feministas, las cuales refieren que por el hecho de ser mujer en una ciudad androcéntrica y patriarcal, nos enfrentamos cotidianamente a discriminación, la cual genera violencia desde la estructural hasta la simbólica y familiar. Esta omisión de género en el currículum de la Escuela de Trabajo Social es una forma de violencia simbólica entendida según Aguilar (2002) como: 
La que se encuentra en la estructura de representaciones simbólico culturales impuesta por los sistemas socioculturales construidos y mantenido desde el andrologocentrismo, el cual es jerárquico y patriarcal, sancionador de toda (o) aquel que no acepta ni ingresa en su estatuto significativo, por medio de actos discriminatorios (Aguilar, p. 57, 2002).

Esta situación se incrementa aún más cuando se refiere a las mujeres en condición de discapacidad, debido a que socialmente se conciben una serie de estereotipos y juicios de valor acerca de lo que es y no es mujer, entre ellos se encuentra la invisibilidad de las necesidades particulares y el poco interés de desarrollar investigaciones y estudiarlas letradamente, demostrado en la falta de contenido en los planes académicos.

De igual manera, las estudiantes refieren que entre las expectativas del curso se encuentran adquirir nuevos conocimientos, sensibilizarse y obtener nuevos insumos para su práctica profesional, no obstante, ellas no mencionan cuales temáticas les gustaría estudiar y analizar durante su formación académica.

Además, a las estudiantes se les preguntó en relación si habían tenido una experiencia cercana a la discapacidad. El 48\% del estudiantado, no la han adquirido. No obstante, el 52\% mencionan que sí, a través de trabajos que han realizado en los diferentes cursos de la carrera, Trabajo Comunal Universitario (TCU), de algunas personas cercanas y finalmente, en la práctica profesional. Sin embargo, en otras preguntas de la encuesta refieren que los contenidos recibidos acerca de las temáticas han sido muy superficiales. De igual manera, se violenta la realidad de la carrera de Trabajo Social, la cual es feminizada.

\section{Perspectiva teórica: los conceptos de género y discapacidad}

Las estudiantes refieren que el concepto de género es una construcción histórica, social y cultural acerca de lo que es ser hombre o mujer de acuerdo con los patrones, roles y comportamientos determinados, relacionados con la socialización y las asignaciones basadas en el sexo. Como se visualizó, las participantes si tienen una idea general sobre las concepciones de género, sin embargo, no lo perciben dentro de sus prácticas cotidianas, debido a que aún ellas no se sienten discriminadas por su condición de ser mujer, y al materializar la situación, produce que no la identifiquen como un asunto de derechos humanos, los cuales según Arroyo (2009) tienen como principio básico que todas las personas nacen libres e iguales en dignidad y derechos. Por tal motivo existe igualdad de derechos, sin importar sexo, etnia, edad, condición de discapacidad, entre otros.

De igual modo, esta misma autora argumenta que los derechos humanos se basan en el valor de la persona humana y por ende: la necesidad de protegerla, la igualdad intrínseca, las necesidades mutuas, respeto y amor por toda vida (Arroyo, 2009).

Así mismo, definen las situaciones de discapacidad como condición especial, limitaciones, carencias, vulnerabilidad, particularidades y no tener las facultades para realizar algunas actividades. De acuerdo con las definiciones presentadas por las participantes, mantienen connotaciones peyorativas, segregantes y discriminatorias, a causa de que se reafirma la cantidad de estereotipos existentes en la sociedad, reforzada por el paradigma tradicional, el cual refiere:

La discapacidad es vista como aquella que necesita protección, atención o asistencia por la caridad. Esta población se encuentra estigmatizada por una serie de prejuicios y mitos que la desvalorizan, los cuales podemos destacar:

- La discapacidad se percibe como una enfermedad "sin remedio".

- Esta población necesita ser asistida por su imposibilidad de valerse por sí misma.

- Son inactivos social y económicamente. No pueden ser independientes.

- $\quad$ No son capaces de asumir su sexualidad, entre otros (Ballestero, 2001). 
Ese paradigma tiene la connotación de marginación, discriminación económica, social y política, dependencia y subestimación de las personas con discapacidad. Por eso, "no se les considera como sujetos de derechos, igual que el resto de la población" (Ballesteros, 2001).

No obstante, las participantes citan frases de idealización de las personas en condición de discapacidad como: iguales, especiales, discriminadas, sujetos de derechos, necesarias, personas con particularidades, muchas veces excluidas, valiosas, seres humanos, vulnerables, emprendedoras, fuertes, perseverantes, emprendedoras, luchadoras, admirables, valientes, esforzadas, ejemplo a seguir, admirables y que superan límites, sobresalientes, muy capaces.

El 96\% de las estudiantes refieren que en los programas de los cursos no hay una sesión exclusiva que analice las situaciones de las mujeres y de las personas en condición de discapacidad. Además, el tiempo asignado para el análisis de este tema no es efectivo. Por lo cual, se invisibiliza una vez más la perspectiva de género en los currículos universitarios; obviamente estos pertenecen a instituciones patriarcales que aún continúan reproduciendo las ramificaciones del poder en los ámbitos educativos.

El $60 \%$ de las estudiantes opinan que no se articulan los contenidos que se proponen en los programas de los cursos con los resultados finales, por ejemplo, se especifican temáticas relacionadas a mujeres, grupos vulnerables, pobreza, discapacidad, entre otros, pero finalmente no se analiza, o simplemente permanece en la bibliografía de dichos programas.

De igual manera, las estudiantes citan que los cursos realizan un aporte básico y superficial de las relaciones de género entre mujeres y hombres, debido a que es una construcción socio-histórica. Con esa afirmación se observa que, las alumnas comprenden la conceptualización teórica de lo que es género; no obstante, omiten la utilización práctica de este.

Las estudiantes indican que en los cursos se permite una investigación y reflexión crítica a través de la teoría cuando se presenta la posibilidad de discutir las temáticas. Además, tienen una relativa comprensión acerca de la legislación y los papeles de aquellos cursos en que se tocan los temas. Sin embargo, no se profundiza en su análisis, y otra vez se observa la presencia de la violencia simbólica mediante la enajenación de las cuestiones de género y discapacidad en las áreas educativas.

Por su parte, la población participante recomienda que la perspectiva de género se pueda incorporar en la escuela a través de talleres y cursos específicos. En relación con el aprendizaje adquirido en aquellos cursos que anteriormente han desarrollado la temática de género y discapacidad, las estudiantes manifiestan que saben sobre los roles establecidos socialmente y las relaciones desiguales, las particularidades de la población en condición de discapacidad, la presencia de la discriminación, el concepto de igualdad de oportunidades e igualdad de género, alguna legislación específica, derechos humanos, construcción socio-histórica, exclusión social y violencia.

Las estudiantes citan que muchos de estos conceptos solamente están presentes en algunos discursos de los y las profesoras, y por ende no se profundiza, además, debe ser un tema de investigación. Por lo anterior, se percibe que la Escuela de Trabajo Social tiene varios acercamientos a la incorporación de las temáticas en análisis, pero aún se continúa amenazada por las capilaridades ocultas del poder patriarcal.

\section{Semejanzas y diferencias entre género y discapacidad}

Las estudiantes detectaron pocas diferencias y semejanzas, sobre todo las que se relacionan con el entorno físico, las características de ser mujer y persona en condición de discapacidad. Por ejemplo, detallan que son distintas en el ámbito de trabajo, salud, educación, luchas por el reconocimiento de derechos, accesibilidad, movilidad, legislación, barreras, autonomía.

No obstante, estos tópicos tienden a transformarse en semejanzas, debido a que en el ámbito laboral aún continúan existiendo discriminación, tanto para las mujeres como para las personas en situación de la discapacidad; en ambas condiciones, se presentan salarios bajos, escasas contrataciones, trabajos informales, carencias en el sistema de seguridad laboral, actitudes segregacionistas y triples jornadas laborales. 
De igual modo, en el campo educativo, tanto las mujeres como la población en discapacidad, reciben segregación por la falta de accesibilidad, actitudinal y física, la insensibilidad para las necesidades particulares y la carencia de una política educativa inclusiva y diversa.

Una situación semejante sucede con el espacio físico, el cual invisibiliza las realidades específicas de la diversidad social. Por ejemplo, existen servicios sanitarios públicos que carecen de aposentos para atender a la niñez o dispositivos que pueden facilitar acciones de limpieza personal para mujeres en condición de discapacidad.

Igualmente, sucede con las diferencias que las estudiantes citan sobre las luchas; las mujeres tenemos más de 500 años de buscar el reconocimiento de nuestros derechos humanos, y las personas en situación de discapacidad iniciaron este proceso desde las décadas remotas donde se pretendía eliminar a estas personas. Además de la constante negociación para la conquista de políticas sociales que brinden la igualdad de derechos para todas las personas.

Las semejanzas propuestas se refieren a la exclusión, violencia, ámbito privado, dependientes, discriminación, subordinación, asexuadas/os, patriarcado, legislación específica, inequidad, desvalorización, condición de vulnerabilidad y estereotipos. El argumento anterior, responde a la existencia de una sociedad totalmente androcéntrica y discriminatoria de aquellos grupos que responden a la diversidad social y genera resistencia al cambio. Por ejemplo, Faith (1999), argumenta que en el momento de ejercer poder, existe resistencia, la cual al mismo tiempo genera cambios éticos y políticos; situación que se visualiza en el fenómeno de la violencia, debido a que la persona violentada ejerce esa resistencia hacia la figura que impone dominio o poder, ya sea contra el cuerpo de una persona o en acontecimientos particulares, como lo es la violencia estructural, simbólica, psicológica, por negligencia y patrimonial, entre otros. Así mismo, la autora enfatiza que esta resistencia ha contribuido para que el feminismo logre cambios en los sistemas patriarcales.

Cabe destacar que este tipo de resistencia se da en la esfera privada, por lo que en palabras de la misma Faith: "la exclusión no es un hecho aislado, las personas han sido separadas a través del discurso de poder y sujetos a técnicas disciplinarias que los clasifican y controlan". Estos hechos se experimentan en aquellos grupos minoritarios, por ejemplo en agrupaciones indígenas, mujeres, homosexuales y personas en condición de discapacidad, las cuales se les restringen sus necesidades específicas por simplemente vivir en una sociedad "normalizada" (Faith, 1999, p.86).

También, Connell (1991), afirma que lo personal es político, por tal motivo, existe un fuerte vínculo entre la experiencia personal y las relaciones de poder, por lo que el Estado no puede imponer políticas sociales desde una perspectiva de género que supuestamente beneficien a sectores feministas, sin visualizar las realidades de mujeres en diferentes ámbitos, como en zonas rurales y mujeres indígenas, estudiantes, entre otras diversidades sociales.

- Finalmente, se concluye que entre las semejanzas se encuentran:

- Pertenecen a un legado histórico generador de discriminación por siglos.

- Son categorías sociales invisibilizadas.

- Estamos envueltas en una ideología dominante y de subordinación.

- Se tienen los mismos derechos y deberes.

- Se participa en todos ámbitos sociales.

- Se busca la igualdad.

- El género y la discapacidad son categorías socialmente construidas.

- Las características físicas son las que generan las diferencias.

- Los mitos y estereotipos son semejantes.

- Cotidianamente buscamos reconocimiento social.

- Se es parte de una diversidad. 


\section{La violencia estructural y la sobreprotección}

Las estudiantes participantes describen el concepto de violencia estructural con imágenes en las representaciones gráficas, como por ejemplo, utilizan mujeres con estándares establecidos por los medios de comunicación, tristes y agobiadas. Así mismo, ellas citan que este tipo de violencia se presenta a través de los chistes, canciones y comentarios que realizan las personas cotidianamente; estos son elementos presentes en dicha definición: "se encuentra en la estructura de representaciones simbólico culturales impuesta por los sistemas socioculturales construidos y mantenido desde el andrologocentrismo, el cual es jerárquico y patriarcal, sancionador de toda (o) aquel que no acepta ni ingresa en su estatuto significativo, por medio de actos discriminatorios" (Aguilar, 2002, p.71).

Este tipo de violencia se reproduce a través de diferentes entidades educativas, por ejemplo, la escuela de Trabajo Social aún carece de las perspectivas de género y discapacidad en su currículo, aunque en el discurso, se mantiene la idea de utilizar ambas categorías en los distintos programas de los cursos. No obstante, las estudiantes reciben seminarios específicos de violencia y recursos humanos, pero el género y la discapacidad no se encuentran como dimensiones transversales.

Por su parte, las instituciones estatales ejercen violencia estructural por el no reconocimiento en los derechos de las mujeres como personas, en los discursos políticos y televisivos, en la academia y gremios profesionales, en las políticas, en los organismos internacionales, en acciones como explotación comercial infantil, la trata y tráfico de personas, en el diseño de algunas edificaciones públicas y privadas, escritos oficiales o informales, en la publicidad, e incluso en artículos tecnológicos.

Cuando se describe los riesgos de la violencia contra las mujeres como un obstáculo para el desarrollo de la sociedad y sobre todo al referirse al crecimiento socioeconómico, cultural o científico, no necesariamente se analiza el bienestar de las personas. Exteriorizar la violencia es entender el ausentismo laboral de las mujeres, su renuncia al trabajo, excluirlas del proceso de contrataciones, entre otras problemáticas; es invisibilizar la inequidad de poder entre géneros; por el contrario lo reafirma (Carcedo, 2001).

Las estudiantes mediante el desarrollo de las diversas sesiones identificaron las manifestaciones de la violencia simbólica y estructural en relación con las personas en condición de discapacidad, mediante las siguientes palabras claves: señalización, burla, descalificación, ayuda, lastima y la segregación; se invisibiliza sus necesidades, su sexualidad, dependencia, preselección para abortar.

También, ellas citaron que la violencia estructural se refleja en los chistes, canciones, abortos terapéuticos, segregación, negación de la sexualidad, tráfico de personas con condición de discapacidad, violencia sutil y estratégica, Igualmente, en la burla social, sobreprotección, formas de vestirse, accesibilidad a los servicios y ofertas del mercado, las tratan como personas niñas o bebés.

Es necesario aclarar que cuando las estudiantes expresaron estas argumentaciones, habían recibido conocimientos previos acerca de la temática con el módulo actual, por lo que se concluye que tienen un manejo de dichos tópicos y reflejan ideas principales de las conceptualizaciones de violencia simbólica, estructural y la sobreprotección. Ninguno de estos conocimientos discutidos por ellas, se habían analizado en otros cursos.

\section{Principios de interpretación sobre los derechos humanos}

Una de las temáticas en discusión fueron los principios de interpretación utilizados en el enfoque de derechos humanos, de los cuales, las estudiantes ya conocían algunos de los contenidos; sin embargo se analizaron de manera teórica y práctica, mediante la simulación de situaciones que violentaban dichos principios, por ejemplo, las estudiantes protagonizaron en un sociodrama a una mujer que fue a buscar empleo y no fue contratada por el hecho de tener hijos en edad escolar, además, interpretaron a una persona con discapacidad al acceder a los servicios de salud, donde se enfrentan a lugares totalmente inaccesibles. 
Las estudiantes visualizaron la violación de derechos aún existentes tanto para las mujeres, como para las personas en condición de discapacidad, a causa del ejerció de poder que ejecuta la mayoría del tejido social; como bien lo cita Hartsock (1983), que la relación de poder generalizada se basa en nuestra cultura de la manera en que se define y acepta la sexualidad desde un género gobernante; es decir, que las mujeres tenemos que vivir una sexualidad hegemónica principalmente masculina. Quizás lo más peligroso de esta situación, consiste en que el mismo principio lógico se refleja en la cotidianeidad de la vida social de las mujeres, en que al mismo tiempo, son reproducidas por la creación de políticas sociales, instituciones públicas o privadas que brindan servicios a la población femenina, bajo los principios de discriminación y segregación social.

De acuerdo con esta misma posición epistemológica, la sexualidad es una acción del poder masculino ejercido hacia las mujeres, al mismo tiempo se desarrolla la ideología de la maternidad como naturaleza y deber social de las mujeres; Albite (2003), manifiesta que en las prácticas políticas y sociales de las mujeres, se les visualizan de acuerdo con el pensamiento dominante de que somos agentes reproductores de la especie humana, las únicas encargadas y equipadas para ejercer la maternidad, crianza y domesticación de la prole, la cual beneficia al mundo masculino.

Esta ideología ha estado tan impregnada en las mujeres, que llega a interiorizarse socialmente, hasta el punto en el cual se cree que si una mujer no se casa a cierta edad y no tiene hijos(as) o presenta alguna situación específica o por simple decisión, no continúa reproduciendo el sistema impuesto de la maternidad domesticada y domesticadora y por ello, se le cuestiona su condición de persona, mujer y ciudadana.

\section{Estrategias propuestas}

Por tanto, las estudiantes consultadas realizan una serie de recomendaciones acerca de las formas de cómo se puede incorporar el género y la discapacidad en los programas de los cursos. Entre ellas se destacan las siguientes:

- Diseño de cursos exclusivos.

- Concientizar al personal docente.

- Visualizar el género y la discapacidad como categoría de análisis dentro de los programas.

- Brindar espacios para el debate de los temas.

- Incentivar investigaciones acerca de las temáticas.

- Crear módulos que profundicen los contenidos.

- Modificación de programas.

- Seminarios exclusivos.

- Realización de talleres.

- Que las y los profesores utilicen estas temáticas en su análisis cotidiano.

- Que se incorporen estos tópicos en la comisión currículum.

- Sesiones específicas para cada uno de los temas.

- Crear conciencia en los y las estudiantes.

\section{Conclusiones}

Una vez explorada la realidad del colectivo participante se concluye y recomienda lo siguiente:

- La presencia parcial y la ausencia de los enfoques de género y discapacidad, son el resultado de la capilaridad del poder patriarcal que se continúa reproduciendo en las instituciones de educación superior; mediante esta actuación se genera violencia estructural y simbólica. 
- Se percibe que las protagonistas no visualizan la restricción en la inclusión de las perspectivas de género y discapacidad, como generadora de violencia simbólica.

- Las estudiantes participantes reconocen las debilidades de las estructuras de los cursos, en cuanto a las temáticas, debido a que en la programación de los mismos, casi no proporcionan bibliografía de autoras, pues no se refieren a los aportes históricos y científicos de ellas y personas en condición de discapacidad. Además, el tiempo asignado para el análisis de este tema no es efectivo.

- Los contenidos que se proponen en los programas de los cursos no se articulan con los resultados finales, por ejemplo, se especifican temáticas relacionadas con mujeres, grupos vulnerables, pobreza, discapacidad, entre otros, pero finalmente no se analiza, o simplemente permanece en la bibliografía de dichos programas.

- Los conocimientos adquiridos con el desarrollo del módulo se asimilaron asertivamente, debido que se reflejaron en la aplicación de las estrategias didácticas de retroalimentación posteriores.

- Existen algunos avances para la inclusión de las categorías de género y discapacidad, sin embargo, las acciones se presentan por la iniciativa de estudiantes y docentes, no mediante una política transversal aunque se encuentre en documentos oficiales de la Escuela de Trabajo Social.

\section{Recomendaciones}

- Es necesario que la Escuela establezca una política que incluya las condiciones de género y discapacidad, en todo su accionar; además, se convierta en un indicador para su reacreditación.

- Se deben facilitar espacios de capacitación, discusión y reflexión en los tópicos de género y discapacidad, para el estudiantado, personal docente y administrativo.

- Promover en los núcleos de investigación existentes la inclusión de los temas en análisis, ya sea a través de las comisiones de trabajos finales de graduación, programa institucional de prácticas académicas o proyectos de docentes.

- Fortalecer y actualizar las iniciativas pasadas, referentes a la incorporación de la perspectiva de género.

- Así mismo, se deben facilitar espacios al interno de la maestría para que se analice conjuntamente los tópicos de discapacidad y género como fundamentos teóricos novedosos y cambiantes.

- Cuando se ejecute otros proyectos semejantes a este, es de suma importancia incorporar al personal docente y administrativo en los estudios. Además, de desarrollar sistematizaciones a lo largo de todo el ciclo lectivo y en los diferentes niveles.

\section{Referencias}

Aguilar, V (2002). La violencia simbólica entretejida en la educación del derecho penal. Maestría de Estudios de la Mujer de la Universidad Nacional y Universidad de Costa Rica. San José, Costa Rica.

Albite, L. y Valle, D (2003). La ideología de la maternidad en la subjetividad femenina: mecanismo de opresión y violencia doméstica. En Loida Martínez y Maribel Tamayo. Género, sociedad y cultura. Puerto Rico, UIPR.

Alfama, E (2009). Hacia la perspectiva de género en el estudio de los movimientos sociales. La participación de las mujeres en la Plataforma en Defensa de l' Ebre. En revista Española de Investigaciones Sociológicas. $N^{\circ} 125$. Pág. 117- 129.

Alfaro, M. Gamboa, A. Jiménez, S. Marín, J. Ramírez, A y Vargas, M (2009). Diversidad estudiantil en $7^{\circ}$ año de la educación secundaria pública costarricense. En revista electrónica Educare. Vol. XIII, No 1. Pág. 27-39. Heredia, Costa Rica.

Araya, S. (2007). De lo invisible a lo cotidiano. Familias y discapacidad. En Revista Electrónica "Actualidades Investigativas en Educación”. Vol.7, N 3. Pág. 1-21. San José, Costa Rica. 
Arroyo, R (2009). Apuntes de clases del curso de derechos humanos. Maestría de violencia intrafamiliar y género de la Universidad Nacional y Universidad de Costa Rica. San José, Costa Rica.

Ballesteros, K y Vega, M (2001). Estrategias que constituyen y aprovechan las personas con discapacidad física para incorporase a los procesos productivos. Tesis para optar por el grado de Licenciatura en Trabajo Social. Universidad de Costa Rica, San José. Costa Rica.

Bolaños C, (1999). Hacia un diseño curricular alternativo en la educación superior. En la Revista de Educación Universidad de Costa Rica. San José, Costa Rica.

Calvo, M (2003). Mujeres con discapacidad: sus percepciones y su vida cotidiana. Estudio de caso de 14 mujeres. Tesis de posgrado, Universidad de Costa Rica, San José, Costa Rica.

Campos, I. Fallas, Y. Molina, M. Morera, N. (2009). Programa Institucional de Prácticas Académicas. Comisión Currículo de Trabajo Social. Universidad de Costa Rica. San José, Costa Rica.

Carcedo, A. (2001). Violencia contra las mujeres: un problema de poder. En Ana Carcedo y Giselle Molina Mujeres contra la violencia: una rebelión radical, pp. 3-16. San José, Costa Rica: CEFEMINA.

Castro, D. (2001). La Discriminación Laboral de las Mujeres Profesionales. Tesis en Licenciatura en Trabajo Social. Universidad de Costa Rica. San José. Costa Rica.

Centro de Investigación en Estudios de la Mujer (2003). Recursos educativos para la docencia y la investigación género-sensitivas. Universidad de Costa Rica. San José, Costa Rica.

Chaves, L. Díaz, M. García, J y otras (2007). Investigación acción colaborativa: un encuentro con el quehacer cotidiano del centro educativo para su transformación. Universidad de Costa Rica, Instituto de Investigación en Educación. San José, Costa Rica.

Díaz, L y Muñoz, P. (2005). Implicaciones de género y la discapacidad en la construcción de la Identidad y Subjetividad. En revistas de Ciencias y Salud. Vol.2, № 002. Pág. 156-167. Bogotá, Colombia.

Faith, K. (1999). Resistencia: sobre Foucault y Feminismo. Traducción de Viviana Solís. Heredia.

Fallas, Y. (2005). Manifestaciones de la discriminación hacia las mujeres en los procesos de enseñanza y aprendizaje en la Universidad de Costa Rica. Tesis de Licenciatura en Trabajo Social. Universidad de Costa Rica. San José, Costa Rica.

González, M (2004). Reconozcamos el sexismo en los procesos educativos. Investigación realizada en el centro de investigación en estudio de la mujer de la Universidad de Costa Rica.

Hartsock, N. (1983). Money, Sex and Power. Northeastern Univertsity Press, Boston.

Herrero, C. (2008). Delincuencia de menores: tratamiento criminológico y jurídico. Madrid: Dykinson.

Jiménez, R. (2003). Conocer y prevenir la violencia intrafamiliar contra las personas con discapacidad. Consejo Nacional de Rehabilitación y Educación Especial. Costa Rica. Heredia, Costa Rica.

Lagarde, M (2001). Claves éticas para el feminismo en el umbral del milenio. En OMNIA estudios de género: México.

Lamas, M (1996). Género: La construcción cultural de la diferencia sexual. Editorial Porrúa. México.

Molina y Ruiz (2004). Desafíos actuales en la enseñanza de la historia, teoría y métodos del Trabajo Social en la Escuela de Trabajo Social de la Universidad de Costa Rica. En Revista de Ciencias Sociales. Universidad de Costa Rica. San José, Costa Rica.

Molina, L (2006). La formación profesional avances y problemáticas que complejizan la construcción de un perfil profesional en la sociedad actual. Boletín electrónico Surá. N 114.

Moreno, M y Guzmán, L (2007). Sistema penal y violencia estructural en Centroamérica: la construcción de un enemigo. Tesis de licenciatura en Derecho. Universidad de Costa Rica. San José, Costa Rica.

Organización Mundial de la Salud (2001). Clasificación Internacional del Funcionamiento de la Discapacidad y de la Salud. Instituto de Migraciones y servicios sociales. Madrid, España.

Ramellini, T. (2004). Para sentir pensar y enfrentar la violencia de género, intrafamiliar y sexual. Instituto Nacional de las Mujeres. San José, Costa Rica. 
Ramírez, M. (2010). Las Dimensiones de Accesibilidad en la Universidad de Costa Rica Sede Rodrigo Facio, un acercamiento desde las Perspectivas de Discapacidad y Género. Maestría Interdisciplinaria sobre Estudios en Discapacidad, Universidad de Costa Rica.

Ramiro, P. (2004). Género y discapacidad. En Seminario violencia de género y discapacidades.

Rivera, A (2004). Violencia intrafamiliar del hombre hacia la mujer. Tesis de Licenciatura. Universidad Autónoma Metropolitana. México. http://wwwenvia.xoc.uam.mx/tid/investigaciones/U/ Violencia\%20intrafamilia. 
